\title{
PENGARUH EFFORT EXPECTANCY, PENGETAHUAN PRODUK DAN TPB TERHADAP NIAT BELI BIBIT TENERA DI KECAMATAN SELESAI
}

\section{The Effect Of Effort Expectancy, Product Knowledge And TPB On Buying Intentions Of Seeds Tenera In Selesai District}

\author{
Abednego Suranta Karo Sekali1 ${ }^{*}$, Julia Ruminta Lumban Gaol ${ }^{1}$ \\ ${ }_{1}^{1}$ Program Studi Agribisnis, Fakultas Agroteknologi, Universita Prima Indonesia \\ Jl. Danau Singkarak Sei Agul, Medan Barat, Medan, Sumatera Utara, 20117 I \\ *E-mail: abednegoks@unprimdn.ac.id
}

\begin{abstract}
ABSTRAK
Produktivitas kelapa sawit petani rakyat masih rendah dibandingkan dengan produktivitas rata-rata Indonesia, untuk meningkatkannya diperlukan bahan tanam kelapa sawit unggul. Bahan kelapa sawit yang berkualitas seperti bibit tenera merupakan salah satu modal utama untuk mendapatkan produktivitas tinggi. Namun pada kenyataannya belum semua petani rakyat menggunakan bibit tenera. Maka dari itu petani perlu didorong untuk menggunakan bibit tenera agar dapat meningkatkan produktivitas kelapa sawit. Penelitian ini bertujuan untuk menganalisis pengaruh effort expectancy, pengetahuan produk dan teori TPB (Theory of Planned Behavior) terhadap niat beli bibit tenera pada petani rakyat di Kecamatan Selesai Kabupaten Langkat Sumatera Utara. Metode yang digunakan untuk penelitian ini adalah SEM-PLS (Structural Equation Modeling). Kesimpulan penelitian antara lain effort expectancy tidak berpengaruh signifikan terhadap Niat Beli. Norma Subjektif berpengaruh signifikan terhadap Niat Beli. Pengetahuan Produk berpengaruh signifikan terhadap Niat Beli, Persepsi Kontrol Perilaku berpengaruh signifikan terhadap Niat Beli. Sikap tidak berpengaruh signifikan terhadap Niat Beli.
\end{abstract}

Kata Kunci : SEM-PLS, Niat Beli, TPB, Effort Expectancy, Pengetahuan Produk

\footnotetext{
ABSTRACT

The productivity of smallholder oil palm is still low compared to the average productivity of Indonesia, to increase it, superior oil palm planting material is needed. Quality oil palm ingredients such as tenera seeds are one of the main assets to get high productivity. But in reality not all smallholder farmers use tenera seeds. Therefore, farmers need to be encouraged to use tenera seeds in order to increase oil palm productivity. This study aims
} 
to analyze the effect of effort expectancy, product knowledge and TPB theory (Theory of Planned Behavior) on the purchase intention of tenera seeds on smallholder farmers in Selesai District, Langkat Regency, North Sumatra. The method used for this research is SEM-PLS (Structural Equation Modeling). The conclusion of the study is that effort expectancy has no significant effect on Purchase Intention. Subjective Norm has a significant effect on Purchase Intention. Product knowledge has a significant effect on Purchase Intention, Perception of Behavioral Control has a significant effect on Purchase Intention. Attitude has no significant effect on Purchase Intention.

Keywords: SEM-PLS, Purchase Intention, TPB, Effort Expectancy, Product Knowledge

\section{PENDAHULUAN}

Tanaman kelapa sawit memiliki nama latin (Elaeis guineensis Jacq) adalah salah satu jenis tanaman perkebunan yang menduduki posisi terpenting di sektor pertanian. Kelapa sawit dapat memproduksi minyak nabati lebih tinggi per hektarnya dibandingkan dengan tanaman perkebunan lainya (Balai Informasi Pertanian, 2000).

Seiring dengan pertambahan luas lahan perkebunan di banyak daerah, membuat Indonesia dapat menjadi produsen terbesar dari tahun 2006 hingga 2008 dengan perbandingan yang cukup besar, hal ini diharapkan dapat terus berkembang sesuai dengan perkembangan mutu serta daya saing industri perkebunan ini. Salah satu strategi yang diyakini mampu meningkatkan daya saing adalah dengan meningkatkan produktivitas dan nilai tambah pada unsurunsur produksi pengolahannya serta perbaikan-perbaikan teknologi, baik pada tingkat on-farm maupun off-farm, termasuk yang berkaitan dengan pengelolaan limbah (www.lrpi.com / 2005).

Produktivitas kelapa sawit perkebunan rakyat Indonesia masih mempunyai peluang untuk perbaikan (Molenaar et al.,2013). Beberapa penelitian telah melaporkan rendahnya produktivitas kelapa sawit disebabkan terjadinya penerapan manajemen yang kurang optimal, seperti penggunaan bahan tanam yang tidak baik (Papenfus, 2002;). Bibit berkualitas tinggi sangat dibutuhkan untuk meningkatkan hasil produktivitas kelapa sawit (Zen et al. 2006). Kualitas bahan tanam (bibit) sangat membentuk jenis buah yang diproduksi dan karenanya kandungan minyak dan kualitas produk.

Ada 3 jenis bahan tanam kelapa sawit, yaitu : (1) Dura; (2) Pisifera dan (3) Tenera. Tenera merupakan benih unggul dimana rata-rata kandungan minyaknya mengandung 30\% lebih banyak minyak per TBS daripada jenis bibit yang lainnya seperti Dura karena rasio mesocarp yang besar dibandingkan endocarp (Corley dan Tinker, 2016). Tenera merupakan suatu teknologi yang belum diadopsi dengan baik pada petani rakyat. Beberapa peneliti melaporkan estimasi kuantitatif dari penggunaan bahan tanam perkebunan rakyat. Laporan dari Jelsma et.al (2017) menyatakan bahwa petani rakyat yang 
menggunakan tenera hanya mencapai $31,7 \%$. Pada 2012, studi sebelumnya yang ditemukan di Provinsi Sumatera Utara, 80,28\% petani mandiri menggunakan bibit yang tidak bersertifikat dan tidak sah atau bibit asalan. Tenera merupakan salah satu teknologi yang telah lama diperkenalkan di Indonesia namun belum dapat diadopsi dengan baik oleh petani rakyat.

Kegiatan pengenalan melalui komunikasi yang efektif lebih diutamakan untuk mengubah perilaku petani agar menjadi lebih berkualitas dalam memilih bibit (Efendi 2004). Penelitian tentang niat menggunakan bibit tenera penting dilakukan untuk meningkatkan produktivitas petani sehingga pemahaman tentang niat tersebut penting untuk dipelajari lebih lanjut. Saat ini pemahaman tentang niat menggunakan khususnya bibit tenera belum sepenuhnya dianalisis dengan baik. Dari penjelasan tersebut maka diperlukan analisis mendalam tentang bagaimana petani mau menggunakan bibit tenera. Oleh karena itu, maka dilakukan penelitian yang bertujuan untuk mengembangkan teori TPB (Theory of Planned Behavior) oleh Ajzen 2005, dengan menggunakan variabel Sikap, Norma Subjektif, Persepsi Kontrol Perilaku, Effort Expectancy, Pengetahuan Produk Terhadap Niat Beli Bibit Kelapa Sawit Varietas Tenera Pada Perkebunan Rakyat (Studi Pada Petani Kelapa Sawit di Kecamatan Selesai Langkat Sumatera Utara)".

\section{METODOLOGI}

Penelitian ini dilakukan di Kecamatan Selesai Kabupaten Langkat, pemilihan lokasi ini telah melakukan berbagai pertimbangan dikarenakan di Kecamatan Selesai memiliki jumlah masyarakat yang bekerja sebagai petani kelapa sawit yang cukup banyak. Penelitian dilakukan tanggal 8 - 17 Juni 2021. Data yang digunakan dalam penelitian ini yaitu dengan mengumpulkan data primer. Dimana data primer adalah mengenai pendapat petani tentang pengaruh effort expectancy dan pengetahuan produk dengan menggunakan teori TPB terhadap niat beli bibit tenera. Sumber data yang diambil adalah petani kelapa sawit yang berada di Kecamatan Selesai. Penelitian ini populasi yang diambil berukuran besar dan jumlahnya tidak diketahui. Dalam penentuan sampel jika populasinya besar dan jumlah populasi tidak ketahui maka menggunakan rumus Rao Purba (2006) digunakan rumus sebagai berikut:

$$
\mathbf{n}: \frac{Z^{2}}{4(m o e)^{2}}
$$

$\mathrm{n} \quad=$ Jumlah sampel

$\mathrm{Z} \quad=$ Tingkat distribusi normal pada taraf signifikansi $5 \%(1,96)$

Moe $=$ Margin of error maksimal $(10 \%)$ atau 0.1 
Maka dari perhitungan rumus diperoleh hasil

$$
\begin{aligned}
& \mathrm{n}: \frac{(1,96)^{2}}{4(0,1)^{2}} \\
& \mathrm{n}: \frac{3,8416}{0,04}
\end{aligned}
$$

n : 96,04 dibulatkan menjadi 96. Namun dalam penelitian ini menggunakan sampel sebanyak 100 responden mewakili petani.

\section{Metode Analisis Data}

Analisis data adalah sebuah proses penyederhanaan data ke dalam bentuk yang lebih mudah dibaca dan diinterpretasikan. Metode yang dipilih untuk analisis data adalah metode SEM-PLS (Structural Equation Model Partial Least Square) yang dioperasikan menggunakan program SmartPLS 3.0. Berikut merupakan langkah-langkah menganalisis data menggunakan SmartPLS 3.0.

a. Pertama melakukan Uji Asumsi dengan mengevaluasi outer model (measurement model): Uji validitas dan uji reliabilitas. Uji validitas adalah ketepatan suatu konstruk yang sedang diuji dengan menguji validitas konstruk menggunakan pendekatan nilai loading factor oleh parameter bobot faktor nilai diatas >0,5 (Hair et al, 2010; Ghozali, 2008). Selain itu harus melakukan uji validitas menggunakan pendekatan convergent validity dengan parameter nilai Average Variance Extracted (AVE) > 0,5 (Jogiyanto dan Abdillah, 2009) dan lalu melakukan pengujian cross loading nilainya harus diatas $>0,6$ (Jogiyanto dan Abdillah, 2009:60).

b. Selanjutnya melakukan uji validitas maka selanjutnya adalah menguji reliabilitas konstruk dengan menggunakan pendekatan Cronbach's Alpha dan Composite Reliability. Parameter yang dipakai adalah nilai Cronbach's Alpha harus bernilai diatas $>0,6$ dan Composite Reliability bernilai diatas $>0,7$. Jika keduanya memenuhi syarat maka dapat dinyatakan bahwa konstruk yang digunakan reliabel (Jogiyanto dan Abdillah, 2009).

c. Lalu lanjut untuk pengujian Model Struktural (Inner Model) dilakukan untuk melihat hubungan antara konstruk, nilai signifikansi dan R-square dari model penelitian. Nilai R-square yang menunjukkan pengaruh satu variabel dengan variabel lainya. Untuk nilai R-square $>75 \%$ dapat dikatakan sangat bagus/tinggi, 50-70 \% dikatakan bagus/tinggi, 25-50 \% dikatakan sedang/moderat, dan $<25 \%$ dikatakan kecil.

d. Pengujian hipotesis merupakan jawaban atas masalah penelitian yang secara rasional deduksi dari teori (Indriantoro dan Supmo, 2002). Uji hipotesis dalam penelitian ini dilakukan dengan alat analisis Partial Least Square (PLS) 3.0. Pengujian hipotesis dapat dilihat dari nilai path coefficient jika Tstatistik $\geq 1,66$ maka nilai tersebut signifikan pada alpha $10 \%$. 


\section{HASIL DAN PEMBAHASAN}

Pada penelitian ini pengumpulan data primer dengan melakukan survey lapangan dan penyebaran kuesioner kepada responden (Petani kelapa sawit). Penyebaran kuesioner dilakukan secara langsung kepada petani rakyat yang ada di Kecamatan Selesai Kabupaten Langkat tersebut. Penyebaran kuesioner kepada responden dilakukan mulai 8-17 Juni 2021. Pada penelitian ini sampel yang dipakai adalah 100 responden yang mewakili petani. Sampel lebih besar dari jumlah minimum dikarenakan ingin menambah akurasi petani

Tabel 1. Karakteristik Responden

\begin{tabular}{lll}
\hline Berdasarkan & Kategori & Jumlah \\
\hline Jenis Kelamat & Laki-laki & 85 \\
& Perempuan & 15 \\
\hline Usia & $30-40$ & 15 \\
& $41-50$ & 25 \\
& $51-60$ & 40 \\
& $>60$ & 20 \\
\hline Pendidikan & SD & 50 \\
& SMP & 30 \\
& SMA & 18 \\
& S1 & 2
\end{tabular}

Sumber : Hasil Penelitian (data primer diolah), 2021.

Tabel 1, memperlihatkan bahwa sebagian besar responden (78\%) adalah pria dan responden wanita (22\%). Responden berdasarkan usia 30-40 tahun berjumlah 15 petani (15\%), responden berusia 41-50 tahun berjumlah 25 petani $(25 \%)$, responden berusia 51-60 tahun berjumlah 40 petani $(40 \%)$, dan responden berusia > 60 tahun berjumlah 20 petani (20\%). Responden penelitian dilihat dari pendidikan terakhir yang paling tinggi adalah Sarjana yaitu 2 petani (2\%), SMA dengan persentase (18\%) sebanyak 18 petani, SMP dengan persentase $(30 \%)$ sebanyak 30 petani dan SD (50\%) sebanyak 50 petani.

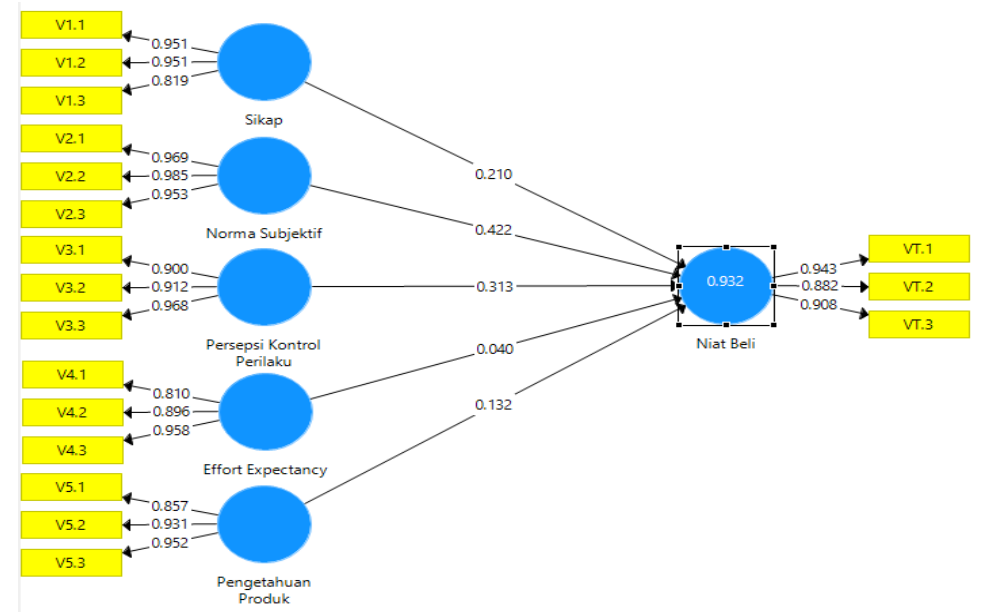

Gambar 1. Uji Loding Faktor 


\section{Pengujian Validitas dengan Pendekatan Nilai Loading Factor}

Outer Model merupakan model pengukuran untuk menilai validitas,parameter model pengukuran (validitas konvergen, validitas diskriminan, composite reliability dan cronbach's alpha) termasuk nilai R2 sebagai parameter ketepatan model prediksi (Jogiyanto dan Abdillah, 2009:57). Gambar 1. menyajikan model penelitian. Model penelitian disajikan dalam software SmartPLS 3.0.

\section{Evaluasi Outer Model (Measurement Model)}

Pada Gambar 1. disajikan output smartPLS yang menyajikan nilai-nilai loading untuk setiap indikator. Suatu indikator pertanyaan dinyatakan valid apabila nilai loading factor > 0,5 (Hair et al, 2010; Ghozali, 2008). Berdasarkan hasil loading factor yang telah dilakukan, maka pada variabel Sikap, Norma Subjektif, Persepsi Kontrol Perilaku, Effort Expectancy dan Pengetahuan Produk dengan nilai loading factor $>0,5$ Sehingga indikator dengan nilai loading factor $>0,5$ tersebut tidak dieliminasi.

\section{Pengujian Validitas dengan Pendekatan Convergent Validity dengan melihat nilai Average Variance Extract (AVE)}

Validitas konvergen berhubungan dengan prinsip-prinsip bahwa pengukur-pengukur dari suatu konstruk seharusnya berkorelasi tinggi. Uji validitas konvergen dalam PLS dengan indikator reflektif dinilai berdasarkan nilai average variance extracted (AVE) lebih dari 0,5 (Jogiyanto dan Abdillah, 2009:60). Berdasarkan table 2, menunjukkan bahwa nilai AVE masing-masing variabel laten lebih dari 0,5 yaitu Effort Expectancy 0,792, Norma Subjektif 0,831, Pengetahuan Produk 0,836, Persepsi Kontrol Perilaku 0,859, Sikap 0,827. Dengan demikian dapat disimpulkan bahwa konstruk memiliki convergent validity yang baik.

Tabel 2. Average Variance Extract (AVE), Cronbach's Alpha dan Composit Reliability

\begin{tabular}{lcccc}
\hline & $\begin{array}{c}\text { Cronbach's } \\
\text { Alpha }\end{array}$ & rho_A & $\begin{array}{c}\text { Composite } \\
\text { Reliability }\end{array}$ & $\begin{array}{c}\text { Average } \\
\text { Variance } \\
\text { Extrated } \\
(\text { AVE })\end{array}$ \\
\hline Effort Expectancy & 0.891 & 0.958 & 0.919 & 0.792 \\
\hline Niat Beli & 0.898 & 0.898 & 0.936 & 0.831 \\
\hline Norma Subjektif & 0.968 & 0.968 & 0.979 & 0.939 \\
\hline Pengetahuan Produk & 0.902 & 0.925 & 0.939 & 0.836 \\
\hline $\begin{array}{l}\text { Persepsi Kontrol } \\
\text { Perilaku }\end{array}$ & 0.917 & 0.921 & 0.948 & 0.859 \\
\hline Siakp & 0.893 & 0.896 & 0.934 & 0.827 \\
\hline
\end{tabular}

Sumber : Pengolahan SEM-PLS, 2021 


\section{Pengujian Reliabilitas dengan Pendekatan Cronbach's Alpha dan Composite Reliability}

Evaluasi reliabilitas di nilai berdasarkan cronbach's alpha dan composite reliability. Tabel 2. menyajikan nilai alpha cronbach dan composite reliability untuk masing-masing variabel laten. Nilai alpha cronbach yaitu di atas 0,6. Sementara nilai batasan composite reliability di atas 0,7 (Jogiyanto dan Abdillah, 2009:60). Berdasarkan tabel 2. menunjukkan bahwa nilai Alpha Cronbach untuk variable Effort Expectancy, Norma Subjektif, Persepsi Kontrol Perilaku, Pengetahuan Produk, Sikap di atas 0.6.

\section{Pengujian Model Struktural (Inner Model)}

Pengujian inner model atau model struktural dilakukan untuk melihat hubungan antara konstruk, nilai signifikansi dan $R$-square dari model penelitian. Model struktural dianalisis dengan menggunakan $R$-square untuk konstruk dependen uji t serta signifikansi dari koefisien parameter jalur struktural. Dalam menilai model struktural dengan PLS dimulai dengan melihat $R$-square untuk setiap variabel laten dependen.

Hasil olah data menggunakan SmartPLS pada Tabel 3. menunjukkan bahwa nilai R-square variabel niat beli adalah sebesar 0,932 atau 93,2 \% yang dipengaruhi oleh variabel Sikap, Norma Subjektif, Persepsi Kontrol Keperilakuan, Effort Expectancy dan Pengetahuan Produk. Sedangkan 0,068 atau $6,8 \%$ dipengaruhi oleh variabel lain diluar yang diteliti.

Tabel 3. R-square

\begin{tabular}{lll}
\hline & R Square & R Square Adjusted \\
\hline Nilai R Square & 0.932 & 0.928 \\
\hline
\end{tabular}

Sumber : Pengolahan SEM-PLSi

\section{Uji Hipotesis}

Setelah dilakukan pengujian validitas dan reliabilitas, selanjutnya dilakukan pengujian hipotesis untuk mengetahui apakah Effort Expectancy, Norma Subjektif, Persepsi Kontrol Keperilakuan, Pengetahuan Produk dan Sikap terhadap niat beli. Signifikansi ukuran yang diestimasi memberikan informasi yang sangat berguna mengenai hubungan antara variabel-variabel penelitian. Dasar yang digunakan dalam menguji hipotesis adalah nilai yang terdapat pada output path coefficients. Dalam PLS pengujian secara statistik setiap hubungan yang dihipotesiskan dilakukan dengan menggunakan simulasi. Dalam hal ini dilakukan dengan metode bootstrap terhadap sampel. Pengujian dengan bootstrap juga dimaksudkan untuk meminimalkan masalah ketidak normalan data penelitian, hasil pengujian dengan bootstrapping dari analisis PLS niat beli. 


\section{Pengujian Pengaruh Effort Expectancy terhadap Niat Beli}

Berdasarkan nilai T-Statistic pada Tabel 4, menunjukkan bahwa hubungan persepsi harga terhadap niat beli adalah bernilai tidak signifikan dengan T-statistic berada di atas 1,66 yaitu sebesar 1,437 dan nilai tidak signifikan $P$ value $<0,1$ yaitu sebesar 0,151 . Nilai original sample estimate adalah positif yaitu sebesar 0,040 yang menunjukkan bahwa hubungan effort expectancy terhadap niat beli adalah positif. Dengan demikian, hipotesis H4 dalam penelitian ini yang menyatakan bahwa "Effort expectancy berpengaruh tidak signifikan terhadap niat beli".

\section{Pengujian Pengaruh Norma Subjektif terhadap Niat Beli}

Berdasarkan nilai T-Statistic pada Tabel 4, menunjukkan bahwa hubungan norma subjektif terhadap niat beli adalah bernilai signifikan dengan $\mathrm{T}$ Statistic berada di atas 1,66 yaitu sebesar 5,835 dan nilai signifikansi $P$ value $>0,1$ yaitu sebesar 0,000 . Nilai original sample estimate adalah positif yaitu sebesar 0.422 yang menunjukkan bahwa hubungan antara norma subjektif terhadap niat beli adalah positif. Dengan demikian, hipotesis H2 dalam penelitian ini yang menyatakan bahwa "Norma Subjektif berpengaruh signifikan terhadap niat beli".

\section{Pengujian Pengaruh Pengetahuan Produk Terhadap Niat Beli}

Berdasarkan nilai T-Statistic pada Tabel 4, menunjukkan bahwa hubungan pengetahuan terhadap niat beli adalah bernilai signifikan dengan Tstatistic berada di bawah 1,66 yaitu sebesar 2,368 dan nilai signifikansi $\mathrm{P}$ value > 0,1 yaitu 0,018 . Nilai original sample estimate adalah positif yaitu sebesar 0,132 yang menunjukkan bahwa hubungan antara hubungan pengetahuan terhadap niat beli adalah positif. Dengan demikian, hipotesis H5 dalam penelitian ini yang menyatakan bahwa "Pengetahuan Produk berpengaruh signifikan terhadap niat beli".

\section{Pengujian Pengaruh Persepsi Kontrol Perilaku terhadap Niat Beli}

Berdasarkan nilai T-Statistic pada Tabel 4, menunjukkan bahwa hubungan persepsi kontrol keperilakuan terhadap niat beli adalah bernilai signifikan dengan T-statistic berada diatas 1,66 yaitu sebesar 3.268 dan nilai signifikansi $P$ value $>0,1$ yaitu sebesar 0,001 . Nilai original sample estimate adalah positif yaitu sebesar 0,313 yang menunjukkan bahwa hubungan antara persepsi kontrol keperilakuan terhadap niat beli adalah positif. Dengan demikian, hipotesis H3 dalam penelitian ini yang menyatakan bahwa "Persepsi Kontrol Perilaku berpengaruh signifikan terhadap niat beli". 


\section{Pengujian Pengaruh Sikap terhadap Niat Beli}

Berdasarkan nilai T-Statistic pada Tabel 4, menunjukkan bahwa hubungan sikap terhadap niat beli adalah bernilai tidak signifikan dengan $\mathrm{T}$ Statistic berada di dibawah 1,66 yaitu sebesar 1,530 dan nilai tidak signifikan $P$ value $>0,1$ yaitu sebesar 0,127 . Nilai original sample estimate adalah positif yaitu sebesar 0,210 yang menunjukkan bahwa hubungan antara sikap terhadap niat beli adalah positif. Dengan demikian, hipotesis H1 dalam penelitian ini yang menyatakan bahwa "Sikap berpengaruh tidak signifikan terhadap niat beli".

Tabel 4. Path Coefficients

\begin{tabular}{|c|c|c|c|c|c|}
\hline & Oiginal Sampe (O) & Sample Menon (M) & Standard Denition (STDE) & TStatisics |OSTSDEN & PVauses \\
\hline Effot Expectony $*$ Natbeli & 0,040 & 0.031 & 0.028 & 1,437 & 0.151 \\
\hline Nomb Subjedtif $>$ Nitbeli & OA.2. & DAOD & 0.072 & 5835 & 0.000 \\
\hline Pengethluan Produde. Nitbeli & 0,132 & 0.128 & 0.056 & 2368 & 0.0 \\
\hline 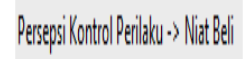 & 0,313 & 0,308 & 0.096 & 3268 & 0.001 \\
\hline Slapp. Notbeli & 0210 & 0.216 & 0.137 & 1,530 & 0.127 \\
\hline
\end{tabular}

Sumber : Hasil Pengolahan SEM-PLS, 2021

\section{Hubungan Effort Expectancy terhadap Niat Beli}

Berdasarkan hasil perhitungan statistik yang telah dilakukan, dapat disimpulkan bahwa konstruk effort expectancy berpengaruh tidak signifikan terhadap niat beli bibit tenera pada petani rakyat. Dengan demikian, hipotesis H4 dalam penelitian ini tidak diterima. Hasil ini menunjukkan bahwa effort expectancy tidak berpengaruh bagi petani kelapa sawit di Kec. Selesai terhadap bibit kelapa sawit jenis tenera, ini dikarenakan petani berpendapat tidak setuju bahwa mudah untuk mempelajari bibit tenera karena belum ada penyuluhan langsung mengenai bibit tenera.

\section{Hubungan Norma Subjektif terhadap Niat Beli}

Berdasarkan hasil perhitungan statistik yang telah dilakukan, dapat disimpulkan bahwa konstruk norma subjektif berpengaruh signifikan terhadap niat beli bibit tenera pada petani rakyat. Dengan demikian, hipotesis H2 dalam penelitian ini berpengaruh signifikan. Hasil ini menunjukkan bahwa norma subjektif berpengaruh bagi petani kelapa sawit di Kec. Selesai terhadap bibit kelapa sawit jenis tenera, ini karena orang-orang sekampung maupun temanteman sepergaulan petani, yang telah berhasil menanam bibit tenera menyarankan petani lain untuk menanam bibit tenera. 


\section{Hubungan Pengetahuan Produk terhadap Niat Beli}

Berdasarkan hasil perhitungan statistik yang telah dilakukan, dapat disimpulkan bahwa konstruk pengetahuan berpengaruh tidak signifikan terhadap niat beli bibit tenera pada petani rakyat. Dengan demikian, hipotesis H5 dalam penelitian ini berpengaruh signifikan. Hasil ini menunjukkan bahwa pengetahuan produk berpengaruh bagi petani kelapa sawit di Kec. Selesai terhadap bibit kelapa sawit jenis tenera, ini karena petani memiliki pengetahuan petani tentang ciri-ciri bibit tenera, mengetahui manfaat dari bibit tenera dan mengetahui kualitas dari bibit tenera

\section{Hubungan Persepsi Kontrol Perilaku terhadap Niat Beli}

Berdasarkan hasil perhitungan statistik yang telah dilakukan, dapat disimpulkan bahwa konstruk persepsi kontrol perilaku berpengaruh signifikan terhadap niat beli bibit tenera pada petani rakyat. Dengan demikian, hipotesis H3 dalam penelitian ini berpengaruh signifikan. Hasil ini menunjukkan bahwa persepsi kontrol keperilakuan berpengaruh signifikan bagi petani kelapa sawit di Kec. Selesai terhadap bibit kelapa sawit jenis tenera, ini karena petani yakin bibit tenera dapat ditanam oleh mereka. Hal ini ditunjukkan dari hasil kuisoner yang dihasilkan dimana petani yang berpendapat bahwa yakin dapat menanam bibit jenis tenera di lahan mereka.

\section{Hubungan Sikap terhadap Niat Beli}

Berdasarkan hasil perhitungan statistik yang telah dilakukan, dapat disimpulkan bahwa konstruk sikap berpengaruh tidak signifikan terhadap niat beli bibit tenera pada petani rakyat. Dengan demikian, hipotesis H1 dalam penelitian ini tidak diterima. Hasil ini menunjukkan bahwa sikap tidak berpengaruh bagi petani kelapa sawit di Kec. Selesai terhadap bibit kelapa sawit jenis tenera, ini karena bibit tenera tidak penting bagi petani karena hasil dan harga penjualan masih relatif rendah dan disamakan dengan harga penjualan bibit dengan jenis yang lain.

\section{KESIMPULAN DAN REKOMENDASI KEBIJAKAN}

\section{Kesimpulan}

Berdasarkan hasil analisis dan pembahasan yang telah dilakukan dalam penelitian ini, telah disampaikan mengenai proses analisis data dan pengujian terhadap keenam hipotesis yang diajukan sesuai dengan justifikasi teoritis yang telah diuraikan, maka peneliti mengambil kesimpulan sebagai berikut.

1. Effort Expectancy tidak berpengaruh terhadap Niat Beli Bibit Tenera

2. Norma Subjektif berpengaruh terhadap Niat Beli Bibit Tenera.

3. Pengetahuan Produk berpengaruh terhadap Niat Beli Bibit Tenera. 
4. Persepsi Kontrol Perilaku berpengaruh terhadap Niat Beli Bibit Tenera.

5. Sikap petani tidak berpengaruh terhadap Niat Beli Bibit Tenera.

\section{Rekomendasi Kebijakan}

Berdasarkan hasil penelitian mengenai Hubungan Sikap, Norma Subjektif, Persepsi Kontrol Perilaku, Effort Expectancy, Pengetahuan Produk melalui Niat beli masih dibutuhkan untuk dikembangkan lebih lanjut penelitian pada masa mendatang. Untuk penelitian selanjutnya disarankan agar melakukan pada objek yang berbeda misalnya pemilihan lokasi ataupun dengan variabel yang berbeda.

\section{Ucapan Terima Kasih}

Saya mengucapkan terimakasih banyak untuk semua pihak yang telah membantu dalam proses jurnal ini terkhusus untuk Universitas Garut telah menerima jurnal saya untuk dipublikasikan, semoga penelitian ini bermanfaat untuk para penelitian selanjutnya

\section{DAFTAR PUSTAKA}

Abdillah., W dan Jogiyanto. 2009. Partial Least Square (PLS) Alternatif SEM Dalam Penelitian Bisnis. Yogyakarta: Penerbit Andi.

Ajzen, I. 2005. Attitudes, Personality, and Behavior. 2ndEdition. New York: Open University Press

Balai Informasi Pertanian (BIP) Irian Jaya. 2000. Lembar Informasi Pertanian (Liptan). No. 109/92. 2 hal.

Corley, R. H. V. and P.B. Tinker. 2016. The Oil Palm. 5 Ed. United Kingdom : Wiley Blackwell..

Ghozali, I. 2008. Structural Equation Modeling Teori Konsep Dan Aplikasi. Semarang :Badan Penerbit Undip.

Jelsma, Idsert, George C. Schoneveld, Annelies Zoomers, and A. C. M. Gus van Westen. 2017. "Unpacking Indonesia's Independent Oil Palm Smallholders: An Actor-Disaggregated Approach to Identifying Environmental and Social Performance Challenges". Land Use Policy69:281-97

Molenaar, Jan Willem, Meri Persch-Orth, Simon Lord, Clive Taylor, and Job Harms. 2013. Diagnostic Study on Indonesian Palm Oil Smallholders: Developing a Better Understanding of Their Performance and Potential. Jakarta: International Finance Corporation.

Papenfus MM. 2002. Investing in oil palm: an analysis of independent smallholder oil palm adoption in Sumatra, Indonesia. , Bogor : Southeast Asia policy research working paper no. 15. ICRAF Southeast Asia.

Rao Purba. 2006. Measuring Consumer Perception Through Factor Analysis. The Asian Manager (February-March).

www.lrpi.com. Kebutuhan Riset Untuk Meningkatkan Daya Saing Industri Kelapa Sawit Indonesia. 2005. Diakses pada 12-04-2021 pukul 20.00 